\title{
Study on Soil Nutrients Spatial Variability in Yushu City
}

\author{
Yueling Zhao ${ }^{1}$, Haiyan $\mathrm{Han}^{2}$, Liying $\mathrm{Cao}^{1}$, and Guifen Chen ${ }^{1, *}$ \\ ${ }^{1}$ Jilin Agricultural University, Changchun, Jilin 130118 \\ ${ }^{2}$ Changchun University, Changchun, Jilin 130022 \\ zyueling@163.com
}

\begin{abstract}
In order to help farmers to understand soil nutrients, use effectively our soil and protect our environment, at the same time to improve sustainable development of the agricultural system, the topsoil samples were collected form yushu city .The ways of combining Geostatistics with GIS were applied to analyze the spatial variability of soil nutrients, such as Alkaline hydrolysis nitrogen, available phosphorus and available potassium. All results shows that Alkaline hydrolysis nitrogen, available phosphorus and available potassium in the coefficient of variation were from $9 \%$ to $46 \%$, and the largest coefficient of variation of available phosphorus was $46 \%$. By using Semi-variogram function of statistical analysis, Alkaline hydrolysis nitrogen, available phosphorus and available potassium show Moderate spatial dependency. The relevance of space about available phosphorus may be the weakest, which is effected mainly by random factors. So the different management and the level of fertilizer may be done according the spatial variability of different area format.
\end{abstract}

Keywords: Geostatistics, soil nutrients, spatial variability, statistical analysis.

The soil is non-uniform complex. The nutrient properties already receive the restriction from natural environment condition, and influenced by artificial actions. The numerous researches indicated that the soil characteristic value have the obvious difference in the different space position. In the 1970s, Burgess and others used statistical method in soil science research area, they had overcome classics Fisher the statistical idea in the research soil space changeability aspect insufficiency [1,2]. In recent years, with the popularization and development of all kinds of technology, more and more scholars considered, the research soil question from the different angles. Many researchers study the soil nutrient spatial distribution and the management by using GPS, GIS and so on correlation technology, some progress has been gain in this field.

The maize filed of yushu city is the main study objective .by using the technology of land statistical method and the model of Geostatistical Analysis in ARCGIS9.2, soil characteristic of spatial variability were studied, which analysis the variability and dependence of soil nutrients properties. The conclusions can sever to precision agriculture, adjust to management manners, protect our resources.

${ }^{*}$ Corresponding author. 


\section{Materials and Methods}

\subsection{Study Area Description}

The study area, yushu city is located in the northern of Jilin province (44 $30^{\prime} 57^{\prime \prime}$ $\left.45^{\circ} 15^{\prime} 02^{\prime \prime} \mathrm{N}, 126^{\circ} 01^{\prime} 44^{\prime \prime} \mathrm{E}-127^{\circ} 05^{\prime} 09^{\prime \prime} \mathrm{E}\right)$, The climate in yushu city belongs to the warm temperate zone, half moist continental monsoon climate, featuring four distinct seasons. Which has cold, long winters and short, mild summer. Yushu city has a mean annual temperature of $4.6^{\circ} \mathrm{C}-5.6^{\circ} \mathrm{C}$ and $500-\mathrm{mm}$ annual rainfall. Soil parent materials in the city are composed of black soil.

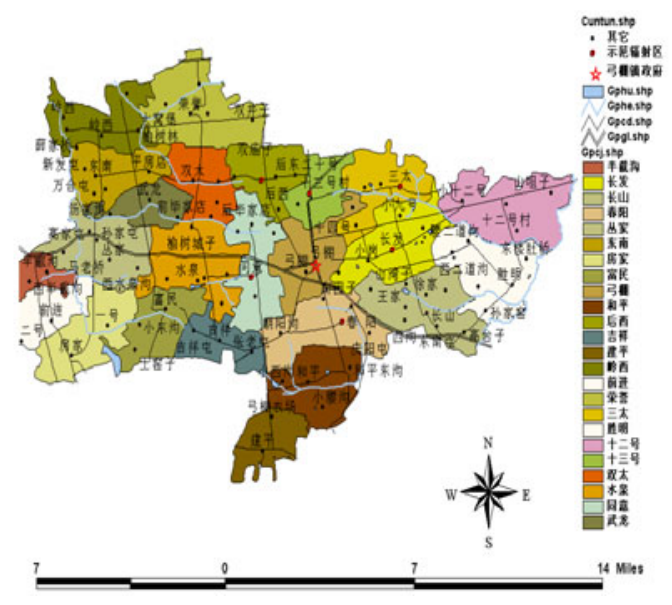

Fig. 1. Location of soil sampling distribution

\subsection{Soil Sampling and Analyses of Nutrients}

A total of 121 topsoil samples were collected in 2008(Fig.1).All sample sites were recorded using Different Global Positioning System (AgGPS-132), the plot has an extension of $1600 \mathrm{~m} 2(80 \mathrm{~m} \times 80 \mathrm{~m})$. All collected samples were put a cool, dry, well ventilated, not special smell and the dust pollution place.

Alkaline hydrolysis nitrogen was gain by using Alkaline hydrolysis diffusion process; available phosphorus in soil was extracted with 0.5 mol L-1 NaHCO3 and determined using the molybdenum blue colorimetric method; available potassium in soil was extracted with 1 mol L-1 NH4OAC and determined using a flamephotometer.

If you have more than one surname, please make sure that the Volume Editor knows how you are to be listed in the author index.

\subsection{Geostatistical Analysis}

The soil was divided into many unform regions in traditional statistic. It describes some soil nutrients by Calculating the mean, standard deviation, the variance, 
coefficient variation and so on of some samples. Geostatistical analysis, amied to describe the variance between the point values sampled in the field. The variable of a region is the key to geostatistical analysis. The main application of geostatistics in soil science has been the estimation and mapping of soil attributes out of sampled areas [3]. Kriging is a linear geostatistical interpolation technique that provides a best linear unbiased estimator for quantities that vary in space. Kriging estimates are calculated as weighted sums of the adjacent sampled concentrations. If data appear to be highly continuous in space, the points closer to those estimated receive higher weights than those that are farther away [4]. Semivariance analysis was used to estimate the range over which samples of the soil nutrient variables were related .The following is Semivariogram formulate.

$$
r(h)=\frac{1}{2 n} \sum_{i=1}^{n}[z(x i)-z(x i+h)]
$$

Where $\mathrm{Z}(\mathrm{xi})$ and $\mathrm{Z}(\mathrm{xi}+\mathrm{h})$ are experimental measures of any two points separated by the vector $h$, and $n$ is the number of experimental pairs separated by $h$.

\subsection{Data Treatment with Computer Software}

Raw data were analyzed with different software packages. the descriptive parameters and the probability analyses were calculated with spss for window(version 16.0) .All maps were produced using GIS software ArcMap(version 9.2)and its spatial analyst and geostatistical analysis extensions.

\section{Results and Discussion}

\subsection{Descriptive Parameters of the Raw-Data Set}

The coefficient of variation (CV) can show the spatial variability in soil science. Normally, if the $\mathrm{CV}$ is $\leq 0.1$, the variable was considered weakly dependent; if the $\mathrm{CV}$ is between 0.1 amd 1 , the variable was considered moderately dependent; and if the $C V \geq 1$, the variable was considered strongly dependent. The main statistical characteristics of the field data set are reported in table. The CV in the city is between $9 \%$ and $46 \%$. The CV of variable phosphorus is the biggest, it gets to $46 \%$. The reason is different farmer have different management Strategies, for example some farmer like to use much more fertilizer, others do not like that.

The CV of the Alkaline hydrolysis nitrogen in the city is $11 \%$, which can be moderately variable. The $\mathrm{CV}$ of the available potassium in the city is $9 \%$, which can be weak variable. The reason is that Alkaline hydrolysis nitrogen and available potassium move easy in soil and they abstract easy by plant. 
Table 1. Descriptive statistics of soil nutrients

\begin{tabular}{cccccccccc}
\hline $\begin{array}{c}\text { Items } \\
\text { mg..g-1 })\end{array}$ & $\begin{array}{c}\text { Sample } \\
\text { points }\end{array}$ & Min & Max & Kurtosis & Skewness & Means & Median & S.D & C.V \\
\hline $\begin{array}{c}\text { Alkaline } \\
\text { hydrolysis N }\end{array}$ & $\mathbf{1 1 8}$ & $\mathbf{1 0 3 .}$ & $\mathbf{1 8 9 . 2}$ & $\mathbf{- 0 . 1 5}$ & $\mathbf{- 0 . 1 1}$ & $\mathbf{1 4 4 . 9}$ & $\mathbf{1 4 5 . 8}$ & $\mathbf{1 6 . 9}$ & $\mathbf{0 . 1 1}$ \\
$\begin{array}{c}\text { Available P } \\
\text { Available K }\end{array}$ & $\mathbf{1 1 8}$ & $\mathbf{5 . 8}$ & $\mathbf{4 4 . 4 6}$ & $\mathbf{9 . 7 4}$ & $\mathbf{2 . 6 3}$ & $\mathbf{1 3 . 0 8}$ & $\mathbf{1 1 . 5 6}$ & $\mathbf{6 . 4 4}$ & $\mathbf{0 . 4 9}$ \\
\hline
\end{tabular}

\subsection{The Test of Soil Nutrient Content Normality}

Kriging is based on normal distribution in geostatistics in soil science. If some data are not normal distribution, some manners must be taken to change them to be normal distribution or close to normal distribution. Because of the reason, the soil nutrients information must be test [5.6]. Kolmogorov-Smirnov(K-S) test for goodness -of-fit was performed to test the normality of the selected soil property distributions. The Alkaline hydrolysis nitrogen, available phosphorus and available potassium were all normally distributed. Their value of Asymp.Sig. (2-tailed) are 0.97,0.08,0.16, respectively. Because they are all bigger than 0.05 , the data set under test is regarded as following a normal distributions. In order to show clearly their normal distribution, some histograms can be drawn by spss software (v 16.0). Histograms of soil nutrients properties with a normal distribution curve are shown in Fig.2-4 ( $\mathrm{n}=118)$.

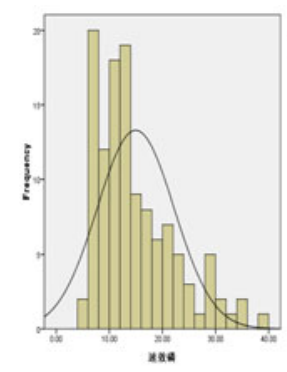

Fig. 2. Histograms of $\mathrm{N}$

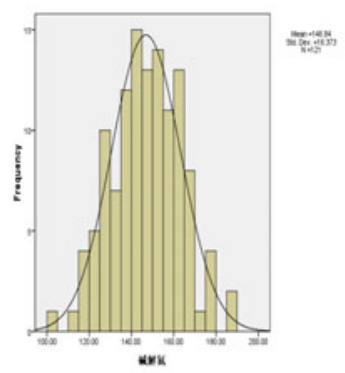

Fig. 3. Histograms of $P$

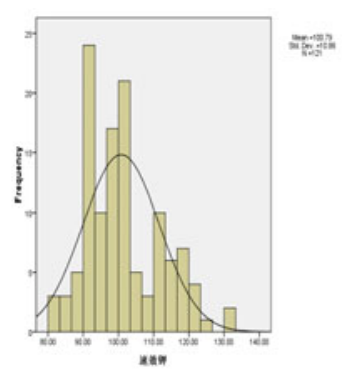

Fig. 4. Histograms of $\mathrm{K}$

\subsection{Semi-variogram Analysis}

To further explore the nature of soil variability, a geostatistical analysis was executed based on Geostatistics. The table 2 shows some main parameters.C0 is the nugget, which express the variable condition when Semi-variogram is in zero point. Partial 
sill is the sum of $\mathrm{C} 0$ and $\mathrm{C}$, which express the total variable in the system including the constitutive variation and the random variation. Partial sill is higher, the total variation is higher. The nugget to sill ratio enables comparison of the relative magnitude of the nugget effect among soil properties [7], especially if sampled at similar scales. If the nugget to sill ratio was $<25 \%$, the variable was considered strongly spatially dependent; if the ratio was between $25 \%-75 \%$, the variable was considered moderately spatially dependent; and if the ratio was $>75 \%$ the variable was considered weakly spatially dependent. Based on the nugget-to-sill ratio, soil nutrient properties in Jilin province yushu city, the spherical model is used well to show the spatial structure of Alkaline hydrolysis nitrogen, available phosphorus and available potassium. The nugget-to-sill ratio are $72 \%, 26 \%, 61 \%$. They shows the nutrient properties are moderate spatial dependence .the structure and random factors make the nutrients properties variable and show some spatial variability.

Table 2. Best-fitted semi-variogram models of soil nutrients and corresponding parameters

\begin{tabular}{cccccc}
\hline Soil properties & $\begin{array}{c}\text { Theoretic } \\
\text { model }\end{array}$ & $\begin{array}{l}\text { Nugget } \\
\mathrm{C}_{0}\end{array}$ & $\begin{array}{l}\text { Partial sill } \\
\mathrm{C}_{0}+\mathrm{C}\end{array}$ & $\mathrm{C}_{0} / \mathrm{C}_{0}+\mathrm{C}$ & Range(m) \\
\hline $\begin{array}{c}\text { Alkaline } \\
\text { hydrolysis nitrogen } \\
\left(\mathrm{mg}_{\mathrm{kg}}{ }^{-1}\right)\end{array}$ & 球状模型 & 72.213 & 214.96 & 0.73 & 12.0762 \\
$\mathrm{AP}\left({\left.\mathrm{mg} . . \mathrm{kg}^{-1}\right)}^{\text {球状模型 }}\right.$ & 11.192 & 49.146 & 0.26 & 26.0162 \\
$\mathrm{AK}\left({\left.\mathrm{mg} . . \mathrm{kg}^{-1}\right)}^{\text {球状模型 }}\right.$ & 100.65 & 163.89 & 0.61 & 12.59 \\
\hline
\end{tabular}

\subsection{Analysis of Soil Spatial Distribution Maps}

Information generated through semi-variogram was used to calculate sample weighing factors for spatial interpolation by a Kriging procedure. In order to model spatial variability and delineate spatial distribution of soil nutrients, geostatistical variogram analysis and Kriging estimation, which provides the best linear unbiased prediction at un-sampled locations, have been widely used [8]. Nutrients concentration estimates can be used to plan spatially variable fertilizer applications $[9,10]$. The maps of alkaline hydrolysis nitrogen (mg.kg-1), available phosphorus (mg.kg-1), available potassium (mg.kg-1)were generated by ARCGIS(v.9.2) software in the study. Spatial patterns of Alkaline hydrolysis $\mathrm{N}$ and Available $\mathrm{K}$ are similar over the study area they are block shape. The spatial distribution of available P show a strip shape. Understanding of soil nutrient spatial variability and possible areas of soil nutrient deficiency in the city are important because it can serve as a basis for planning management strategies to improve crop yields and reduce environmental impact, particularly, which will benefit the sustainability of the agricultural system. 


\section{Conclusions}

The results shows that Alkaline hydrolysis nitrogen, available phosphorus and available potassium in the coefficient of variation were from $9 \%$ to $46 \%$, and the largest coefficient of variation of available phosphorus was $46 \%$. Alkaline hydrolysis nitrogen and available potassium are normally distributed. available phosphorus is nearly normally distributed, which has very big Kurtosis and Skewness. The phenomenon show the data is not normally distributed well. But the soil nutrients properties are in good condition, there are more stronger Potential in next years.

The constitutive factors and the random factors results to soil spatial variability .By using Semivariance function of statistical analysis, Alkaline hydrolysis nitrogen, available phosphorus and available potassium show Moderate spatial dependency. The contribution of constitutive factors in the following order: available phosphorus > available potassium $>$ Alkaline hydrolysis nitrogen. The variability of available phosphorus is mainly effected by constitutive factors. Because the character of phosphorus moving slow in soils. The relevance of space about available phosphorus may be the weakest, which is effected mainly by random factors. The different management and the level of fertilizer may be done according the different spatial variability of area.

We can get the spatial distributions of Alkaline hydrolysis nitrogen, available phosphorus and available potassium generated form their semi-variograms . There are not same nutrient distribution in different farmland form the Kriging maps by GIS. The prediction maps of Alkaline hydrolysis nitrogen, available phosphorus and available potassium were generated using ordinary Kriging methods .The different samples exist different spatial distributions in the maize fields of yushu city, but there are a certain principle in the samples. For example, some show strip shape, other show block shape. Nutrients concentration estimates can be used to plan spatially variable fertilizer applications and plan different management strategies.

Acknowledgment. This research was supported in part by the National High-Tech Research and Development plan of China.NO. 2006AA10A309, the National Spark Program NO.2008GA661003H and by the Youth Foundation of Jilin Agricultural University under Grant No.2010041.

\section{References}

1. Rodríguez, A., Durán, J., Fernández-Palacios, J.M., Gallardo, A.: Spatial variability of soil properties under Pinus canariensis canopy in two contrasting soil textures. Plant Soil 322, $139-150$ (2009)

2. Brocca, L., Morbidelli, R., Melone, F., et al.: Soil moisture spatial variability in experimental areas of central Italy. Journal of Hydrology 333, 356-373 (2007)

3. Goovaerts, P.: Geostatistics in soi science: state-of-the-art and perspectives. Geoderma 89(1-2), 1-45 (1999)

4. Gressie, C.: The origins of Kriging Math. Geol. 22(2), 239-252 (1990) 
5. Yang, Z.J., Wei, J.S., He, P., et al.: Spatial variance of potassium in rubber plantation soil in danzhou city of Hainan province. Journal of Northwest Forestry University 25(5), 41-44 (2010)

6. ZhaoL, M., Shi, X.Z., Huang, Y., et al.: Influential factors of spatial heterogeneity of soil nutritious in taihu lake region soils. Soils 40(6), 1008-1012 (2008)

7. Zhao, J., Zhang, J.M., Ming, K., et al.: Spatial heterogeneity of soil nutrients in blacksoil,China -a case study at hailun county. Bulletin of Soil and Water Conservation 24(6), 53-57 (2004)

8. Zhang, M., He, P.F., Chen, W.Q.: Spatio-temporal variability analysis of soil nutrients based on GIS and geostatistic. Journal of Northeast Agricultural University 41(3), 53-58 (2010)

9. Lark, R.M., Ferguson, R.B.: Mapping risk of soil nutrient deficiency or excess by disjunctive and indicator kriging. Geoerama 118, 39-53 (2004)

10. Bai, Y.L., Jin, J.Y., Yang, L.P., et al.: Variability of Soil Nutrients in Field and Fertilizer Recommendation. Plant Nutrition and Fertilizer Science 7(2), 129-133 (2001) 